\title{
Gait Speed at Discharge and Risk for Readmission or Death: A Prospective Study of an Emergency Ward Population
}

This article was published in the following Dove Press journal: Open Access Emergency Medicine

\author{
Daniel Hertzberg $\mathbb{( D}^{1,2}$ \\ Yauheni Luksha ${ }^{3, *}$ \\ Ismail Kus $\mathbb{1 D}^{3, *}$ \\ Parto Eslampia ${ }^{3}$ \\ John W Pickering (D) ${ }^{4}$ \\ Martin J Holzmann (iD) ${ }^{1,3}$ \\ 'Department of Medicine, Karolinska \\ Institutet, Solna, Stockholm, Sweden; \\ ${ }^{2}$ Department of Perioperative Medicine \\ and Intensive Care, Karolinska University \\ Hospital, Solna, Stockholm, Sweden; \\ ${ }^{3}$ Functional Area of Emergency Medicine, \\ Karolinska University Hospital, Huddinge, \\ Stockholm, Sweden; ${ }^{4}$ Department of \\ Medicine, University of Otago \\ Christchurch, and Emergency \\ Department Christchurch Hospital, \\ Christchurch, New Zealand \\ *These authors contributed equally to \\ this work
}

\begin{abstract}
Background: There has been a growing interest in measuring gait speed for assessing longterm mortality and risk for hospital readmission in different populations.

Objective: We studied the association between a 10-meter gait speed test at hospital discharge and the risk for 30- and 90-day hospital readmission or death in a mixed population of patients hospitalized for emergency care.

Patients and Methods: Patients were prospectively included from 5 wards at the Karolinska University Hospital. The 10-meter gait speed test was measured on the day of discharge. Statistical analysis was performed using logistic regression.

Results: A total of 344 patients were included. Forty-one patients $(n=41)$ were readmitted to hospital or died within 30 days, and 81 were readmitted or died within 90 days after discharge. Readmitted patients were older and had more comorbidities. A $0.1 \mathrm{~m} / \mathrm{s}$ reduction in gait speed was associated with a $13 \%$ greater odds of readmission or death within 30 days (OR 1.13 [95\% CI $1.00-1.26])$. The area under the receiver operating characteristic curve (AUC) was 0.59 (95\% CI $0.51-0.68$ ). The results were similar for 90 -day readmission or death where a $0.1 \mathrm{~m} / \mathrm{s} \mathrm{decrement}$ in gait speed was associated with an OR of 1.13 (95\% CI 1.04-1.24). When age, eGFR, hemoglobin concentration, and active cancer, which all were univariate predictors of 30-day readmissions, were added to the model it yielded an AUC of 0.68 (95\% CI 0.60 to 0.77).

Conclusion: In a mixed population of patients hospitalized for emergency care, low gait speed at discharge was associated with an increased risk of 30- and 90-day readmission or death. However, the test did not discriminate well between those who were readmitted or died and those who did not; therefore we do not recommend its use as a stand-alone test in this population.
\end{abstract}

Keywords: gait speed, patient readmission, hospitalization

\section{Introduction}

Early readmissions are common and associated with patient distress and increased costs for health-care systems. In the United States, the 30-day and 90-day readmission rates are approximately $20 \%$ and $34 \%$, respectively. ${ }^{1}$ In addition, readmissions within 30 days of discharge are used as a metric for quality-of-care in the US. $^{2}$ Readmissions put strain on health care organizations by contributing to emergency department crowding, and to a high hospital bed occupancy. This highlights the need for preventive strategies aimed at reducing readmissions. Before these may be developed or interventional studies undertaken to test them, there is a need to develop prediction models to identify patients at high risk of readmission.
Correspondence: Daniel Hertzberg Department of Medicine, Karolinska University Hospital, Solna SE-I7I 76, Stockholm, Sweden

Tel +46851770000

$\mathrm{Fax}+46851775810$

Email daniel.hertzberg@ki.se 
Physicians base their decisions to discharge patients, among other things, on their assessment of risk for early readmission. In most cases, this is done by using "gestalt", which is based on the physicians' previous experience. However, it has been found that the ability for health care professionals to predict readmissions in older patients is poor. ${ }^{3}$ Attempts have been made to identify risk factors for patient readmission, especially after myocardial infarction and heart failure, ${ }^{4-6}$ but there are currently no established prediction models that provide a good risk assessment. ${ }^{7}$ However, a recent study on a pediatric population presented a promising prediction model with an area under the receiver operating characteristic curve (AUC) of $0.79 .^{8}$

There has been a growing interest in measuring gait speed for assessing motor function and long-term mortality. ${ }^{9}$ It is thought to be a surrogate marker for frailty, and has even been called a new vital sign. ${ }^{10,11}$ Information about the association between gait speed and risk of hospital readmission is scarce; only two studies have suggested such an association. ${ }^{10,12}$ However, both studies investigated specific patient groups. Namely, patients with chronic obstructive pulmonary disease or with myocardial infarction. ${ }^{10,12}$ To the best of our knowledge, there is no study published which investigated gait speed as a predictor for readmissions in a mixed population of patients hospitalized for emergency care. Therefore, we aimed to study the ability of a simple test, namely measuring the time it takes to walk 10 meters, to predict risk of early readmissions.

\section{Patients and Methods Study Population}

The study was a prospective observational cohort study including patients from 5 hospital emergency wards caring for patients admitted for surgical, cardiological, infectious, or internal medicine emergencies at the Karolinska University Hospital, Huddinge between February 13, 2017, and October 27, 2017. Inclusion of patients was done office hours on weekdays by the authors Y.L., I.K. and research assistants not involved in the care of the patients. Patients were only eligible for inclusion after the decision to discharge had been made by the attending physician. Eligible for inclusion were patients i) admitted from the emergency department, ii) for whom a decision to be discharged home had been made, iii) who were $\geq 50$ years of age and, iv) who were able to give written informed consent, v) who were expected to be able to walk 10 meters with or without walking aid, vi) were not admitted for an orthopedic injury, and vii) were expected to live $>6$ months. Patients were excluded if they i) were not able to complete the gait speed test ii) were not discharged after the decision to discharge them had been taken, or iii) those who were discharged elsewhere than home, for example to geriatric rehabilitation, and iv) those who were living outside Stockholm County Council of whom we were not able to follow up; Figure 1.

A power calculation was performed. With information from an earlier pilot study, we expected a rate of readmission within 3 months of $20 \%$. We assumed that approximately $20 \%$ would be exposed to slow gait speed $(<0.55 \mathrm{~m} / \mathrm{s})$. Using an $\alpha=0.05$, power of $90 \%$ and effect size of $30 \%$ difference in event rate between the exposed and the unexposed we would need to include 500 patients.

The study was conducted in accordance with the Declaration of Helsinki. The regional ethics committee in Stockholm approved of the study, and all patients gave their written informed consent to participate in the study.

\section{The 10-meter Gait Speed Test}

After inclusion, the patients performed the 10-meter gait speed (10MGS) test as follows. A 10-meter distance was marked in the wards' corridors on the floor with tape. The patients were asked to walk in their normal pace over the marked 10 meters. The patients started from standing still (static start) and were allowed to use their usual walking aids. The walking test was performed once. The time to walk 10 meters was measured in seconds with a stopwatch, a method earlier shown to be reliable. ${ }^{13}$ The time to finish the 10 -meter gait speed test was converted to velocity in meters per second as follows: 10 -meter gait speed $(\mathrm{m} / \mathrm{s})=10 \mathrm{~m} /$ seconds to finish walking test.

\section{Data Collection and Definitions}

Information on habitual walking abilities and self-rated health was gathered through questionnaires which patients filled out after being included in the study. Information on hospital readmissions and background characteristics were retrieved from medical records. Follow-up information was gathered from all 5 hospitals in Stockholm county. 30- and 90-day readmission was defined as any nonelective readmission $\leq 30$ and $\leq 90$ days, respectively, following the hospital discharge. Those who died during follow-up were regarded as being readmitted, since they would have come to the hospital if able. Previous hospitalizations with the following discharge diagnoses were used to define comorbidities: atrial fibrillation, chronic obstructive pulmonary disease, diabetes, heart failure, 


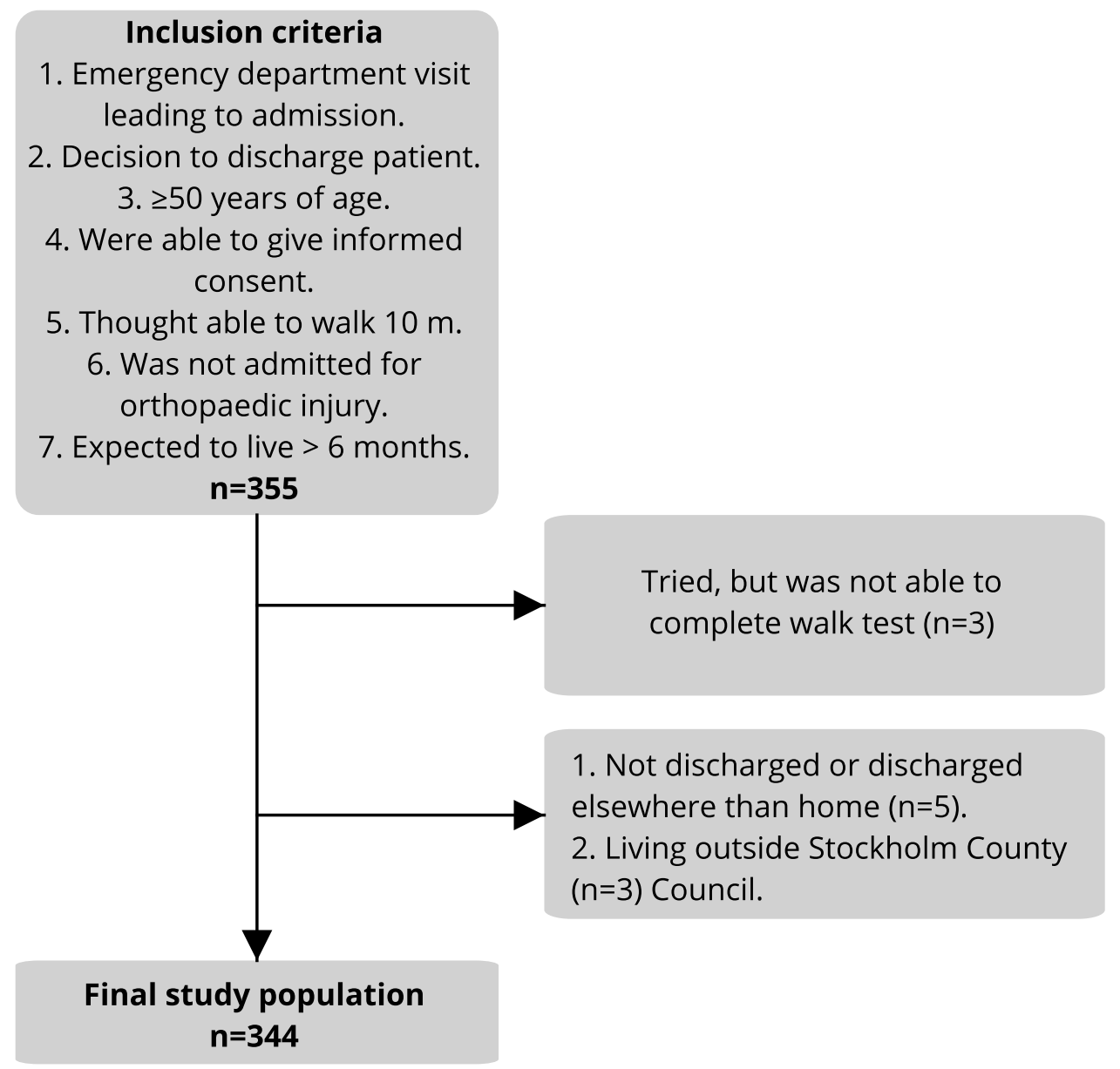

Figure I Selection criteria for the study population.

myocardial infarction, stroke at any time point. Active cancer was defined as a hospital stay with a diagnosis of any cancer in the previous 2 years. All other variables reflected the current status during the hospital stay. Vital signs and laboratory values used were those closest in time to discharge. Body mass index was defined as the weight (kg) divided by height (meter) squared. Walking aid was defined as use of any type of walking aid. Glomerular filtration rate was estimated according to the Chronic Kidney Disease Epidemiology collaboration equation. ${ }^{14}$ In the electronic patient records, the primary discharge diagnoses are coded according to the Swedish edition of the international classification of diseases revision $10 .^{15}$ The diagnoses were in this study reported as the level of three-character categories and included all its subcategories (for example I50 includes I50.9).

\section{Statistical Analysis}

Baseline characteristics were described as numbers and percentages for categorical variables and means and standard deviations for continuous variables. The primary outcome measure was readmission to hospital or death within 30 days and the secondary outcome measure was readmission to hospital or death within 90 days. The association between background characteristics and the outcomes was analyzed using logistic regression. The association between the exposure 10-meter gait speed and the 30- and 90-day nonelective hospital readmissions or death was analyzed using logistic regression. Odds ratios for readmission were calculated for a $0.1 \mathrm{~m} / \mathrm{s}$ reduction in gait speed, and were reported with 95\% confidence intervals. To check for a nonlinear association between 10-meter gait speed and 30-day readmission, the 10-meter gait speed was flexibly modelled using restricted cubic splines with 3 knots. The association between the splines and the outcome was then evaluated. The AUC of gait speed was calculated for each outcome. The gait speed test was hypothesized to be a clinical test serving as a compound variable for comorbidity burden and possibly developing disease associated with readmission. We, therefore, aimed to study the association between gait 
speed and readmission as an unadjusted analysis. Data management and statistical analysis were performed using Stata version 15 (StataCorp LP, College Station, TX).

\section{Results}

\section{Study Population}

Due to slow recruitment, the study was stopped prematurely. There were 355 patients who met the study criteria, 3 were excluded because they lived out of the area, 3 more failed to complete the 10MGS test and 5 were not discharged on the day as expected, leaving a final study population of 344 patients. The distribution of the 10meter gait speed test results is presented in Figure 2. The mean 10-meter gait speed was $0.9 \mathrm{~m} / \mathrm{s}$ (standard deviation $0.3 \mathrm{~m} / \mathrm{s}$ ). Patient characteristics according to quartiles of gait speed are presented in Table 1. Compared to the quartile with the highest gait speed, patients in the quartile with the lowest gait speed were older, had lower estimated glomerular filtration rate (eGFR), lower hemoglobin concentration, had more often heart failure, chronic obstructive pulmonary disease (COPD), previous stroke, were more likely to be living alone, were more often in need of home care service, and reported a shorter maximum walking distance, and reported an ability of climbing less numbers of stairs before stopping. The most common primary discharge diagnoses were acute myocardial infarction $8.8 \%(\mathrm{n}=30)$, heart failure $8.8 \%(\mathrm{n}=30)$ and atrial fibrillation/flutter $8.2 \%(\mathrm{n}=28)$. The 20 most common primary discharge diagnoses are presented in Supplemental Table 1. The number of patients included from the

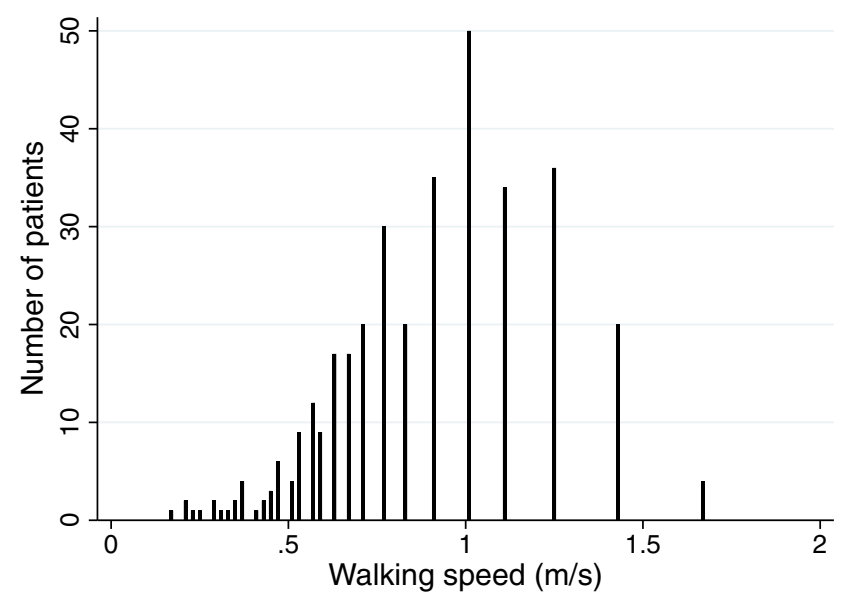

Figure 2 Distribution of patient's 10 -meter gait speed test. The gait speed was calculated as the walking distance $(10 \mathrm{~m})$ divided by the time in whole seconds to complete the test. The bars are closer to each other in the low walking speeds since the variety of possible slow walking speeds are unlimited, which is on the contrary to fast walking speeds. emergency wards was: surgical ward; $n=63$, internal medicine ward; $n=160$, cardiology ward; $n=113$, infectious diseases ward; $\mathrm{n}=8$.

\section{0-Day Outcome}

In total, 39 patients were readmitted to hospital within 30 days and two others died within 30 days meaning $12 \%$ $(n=41)$ of patients met the primary outcome measure. The mean 10 -meter gait speed in these patients was $0.8 \mathrm{~m} / \mathrm{s}$ (SD 0.26), compared to $0.9 \mathrm{~m} / \mathrm{s}$ (SD 0.30) in patients who were not readmitted (Figure 3 ). In the quartile with highest gait speed, 5\% $(\mathrm{n}=3)$ were readmitted within 30 days, compared with $16 \%(n=15)$ patients in the quartile with the slowest gait speed.

There was a significant association between gait speed and 30-day readmissions or death. Each $0.1 \mathrm{~m} / \mathrm{s}$ reduction in gait speed was associated with an $13 \%$ greater risk of 30-day readmissions or death (OR 1.13 [95\% CI 1.00 to 1.26]). There was no sign of a nonlinear relationship between 10-meter gait speed and the 30-day outcome (Supplemental Figure 1). The odds for readmission was 3.6 times higher in the quartile with the slowest walkers compared with the quartile with the fastest walkers (OR 3.56 [95\% CI 0.99 to 12.88$]$ ).

The AUC was 0.59 (95\% CI 0.51 to 0.68 ) for readmission or death within 30 days for gait speed (Figure 4, Model 1). When age, eGFR, hemoglobin concentration, and active cancer, which all were univariate predictors of 30-day readmissions, were added to the logistic regression model it yielded an AUC of 0.68 (95\% CI 0.60 to 0.77 ) (Figure 4, Model 2).

3 of 60 patients with a gait speed of $1.2 \mathrm{~m} / \mathrm{s}$ or higher were readmitted within 30 days, yielding a negative predictive value of $95 \%$ ( $95 \%$ CI $86 \%$ to $99 \%$ ). However, no gait speed cut-off value was found with both a sensitivity and specificity high enough to be of clinical value (Supplemental Table 2).

In univariate analyses, the following variables predicted 30-, and 90-day readmissions; age, eGFR, hemoglobin concentration, active cancer (Table 2). When including gait speed, age, eGFR, $\mathrm{Hb}$, and active cancer in a multivariable model, none of the variables showed sign of independence and the confidence intervals passed 1.00.

\section{0-Day Outcome}

In total, $24 \%(n=81)$ of the patients were readmitted to hospital $(\mathrm{n}=72)$ or died $(\mathrm{n}=9)$ within 90 days. The mean 10-meter gait speed in these patients readmitted within 90 
Table I Baseline Characteristics of the Study Population According to I0-Meter Walking Speed Quartiles

\begin{tabular}{|c|c|c|c|c|c|}
\hline & $\begin{array}{l}\text { All Patients } \\
(n=344)\end{array}$ & $\begin{array}{l}\text { QI } \\
\geq 1.25 \mathrm{~m} / \mathrm{s} \\
(\mathrm{n}=60)\end{array}$ & $\begin{array}{l}\text { Q2 } \\
I .11-1.00 \mathrm{~m} / \mathrm{s} \\
(n=84)\end{array}$ & $\begin{array}{l}\text { Q3 } \\
0.9|-0.7| \mathrm{m} / \mathrm{s} \\
(n=\mid 05)\end{array}$ & $\begin{array}{l}\text { Q4 } \\
\leq 0.67 \mathrm{~m} / \mathrm{s} \\
(\mathrm{n}=95)\end{array}$ \\
\hline Age, years, mean (SD) & $70(11)$ & $64(8.5)$ & $67(10)$ & $72(11)$ & $74(12)$ \\
\hline Female sex, n (\%) & 145 (42\%) & $23(38 \%)$ & $32(38 \%)$ & $40(38 \%)$ & $50(53 \%)$ \\
\hline Pulse, beats/minute*, mean (SD) & $73(15)$ & $70(11)$ & $72(14)$ & $74(17)$ & $73(15)$ \\
\hline Systolic blood pressure*, mmHg, mean (SD) & $13 \mid(19)$ & $130(13)$ & $130(2 \mid)$ & $130(18)$ & $133(20)$ \\
\hline Diastolic blood pressure*, mmHg, mean (SD) & $76(12)$ & $77(11)$ & $77(13)$ & $76(12)$ & $73(12)$ \\
\hline Respiratory rate*, breaths/min, mean (SD) & $17(4.8)$ & $17(3.1)$ & $16(3.5)$ & $18(3.5)$ & $19(7.2)$ \\
\hline Oxygen saturation*, percent, mean (SD) & $97(2.4)$ & $98(1.8)$ & $98(2.0)$ & $97(2.6)$ & $97(2.8)$ \\
\hline Body temperature*, ${ }^{\circ} \mathrm{C}$, mean (SD) & $37(0.5)$ & $37(0.5)$ & $37(0.6)$ & $37(0.5)$ & $37(0.6)$ \\
\hline Body mass index*, $\mathrm{kg} / \mathrm{m}^{2}$, mean (SD) & $27(5.4)$ & $26(4.0)$ & $27(5.3)$ & $26(4.8)$ & $28(6.8)$ \\
\hline Serum C-reactive protein*, mg/L, mean (SD) & $29(40)$ & $26(4 I)$ & $22(3 I)$ & $36(47)$ & $29(36)$ \\
\hline Serum sodium conc. *, mmol/L, mean (SD) & $139(3.3)$ & $139(2.7)$ & $139(2.8)$ & $139(3.2)$ & $140(4.1)$ \\
\hline Serum potassium conc. *, mmol/L, mean (SD) & $4.0(0.5)$ & $4.0(0.4)$ & $4.0(0.5)$ & $4.0(0.4)$ & $3.9(0.5)$ \\
\hline Serum creatinine conc. $*, \mu$ mol/L, mean $(S D)$ & $97(61)$ & $82(25)$ & $86(33)$ & $109(87)$ & $101(60)$ \\
\hline eGFR $\mathrm{mL} / \mathrm{min} / \mathrm{l} .73 \mathrm{~m}^{2 *}$, mean (SD) & 7I (23) & $81(17)$ & $77(19)$ & $66(25)$ & $65(25)$ \\
\hline$>60 \mathrm{~mL} / \mathrm{min} / \mathrm{l} .73 \mathrm{~m}^{2}, \mathrm{n}(\%)$ & $24 \mid(7 \mid \%)$ & $53(88 \%)$ & $67(82 \%)$ & $64(61 \%)$ & $57(60 \%)$ \\
\hline $45-60 \mathrm{~mL} / \mathrm{min} / \mathrm{l} .73 \mathrm{~m}^{2}, \mathrm{n}(\%)$ & $46(14 \%)$ & $5(8.3 \%)$ & $9(11 \%)$ & $16(15 \%)$ & $16(17 \%)$ \\
\hline$<45 \mathrm{~mL} / \mathrm{min} / \mathrm{l} .73 \mathrm{~m}^{2}, \mathrm{n}(\%)$ & $55(16 \%)$ & $2(3.3 \%)$ & $6(7.3 \%)$ & $25(24 \%)$ & $22(23 \%)$ \\
\hline Serum leucocyte conc. ${ }^{*}$, no. $\times 10^{9} / \mathrm{L}$, mean (SD) & $8.0(4.1)$ & $7.3(2.6)$ & $7.5(2.6)$ & $8.9(6.0)$ & $7.9(3.4)$ \\
\hline Haemoglobin conc. $*, g / L$, mean $(S D)$ & $125(20)$ & $130(19)$ & $129(22)$ & $124(2 \mid)$ & $118(17)$ \\
\hline Previous myocardial infarction**, n (\%) & $68(20 \%)$ & $10(17 \%)$ & $15(18 \%)$ & $19(18 \%)$ & $24(25 \%)$ \\
\hline Heart failure**, n (\%) & $84(24 \%)$ & $4(6.7 \%)$ & $13(16 \%)$ & $28(27 \%)$ & $39(41 \%)$ \\
\hline Diabetes**, n (\%) & $82(24 \%)$ & $12(20 \%)$ & $9(11 \%)$ & $32(31 \%)$ & $29(31 \%)$ \\
\hline Chronic obstructive pulmonary disease ${ }^{* *}, \mathrm{n}(\%)$ & $51(15 \%)$ & $\mathrm{I}(\mathrm{I} .7 \%)$ & $9(11 \%)$ & $20(19 \%)$ & $21(22 \%)$ \\
\hline Atrial fibrillation/flutter**, n (\%) & $86(25 \%)$ & $10(17 \%)$ & $17(20 \%)$ & $28(27 \%)$ & $31(33 \%)$ \\
\hline Active cancer**, n (\%) & $60(18 \%)$ & $13(22 \%)$ & $12(14 \%)$ & 14 (I4\%) & $21(22 \%)$ \\
\hline Previous stroke**, n (\%) & $35(10 \%)$ & $\mathrm{I}(\mathrm{I} .7 \%)$ & $8(9.5 \%)$ & $14(13 \%)$ & $12(13 \%)$ \\
\hline Living alone***, n (\%) & I 44 (42\%) & $14(23 \%)$ & $32(39 \%)$ & 48 (46\%) & $50(53 \%)$ \\
\hline Home care service ${ }^{* * *}, \mathrm{n}(\%)$ & $29(9.1 \%)$ & $0(0 \%)$ & $\mathrm{I}(\mathrm{I} \%)$ & $2(2 \%)$ & $26(29 \%)$ \\
\hline \multicolumn{6}{|l|}{ Self-reported use of walking aid*** } \\
\hline Never, n (\%) & 245 (7I\%) & $60(100 \%)$ & 77 (92\%) & 70 (67\%) & $38(40 \%)$ \\
\hline Sometimes, n (\%) & 49 (14\%) & $0(0.0 \%)$ & $7(8.3 \%)$ & $22(21 \%)$ & $20(21 \%)$ \\
\hline Always, n (\%) & $50(15 \%)$ & $0(0.0 \%)$ & $0(0.0 \%)$ & $13(12 \%)$ & 37 (39\%) \\
\hline \multicolumn{6}{|l|}{ Self-reported walking distance $* * *$} \\
\hline$>1000$ meter, $\mathrm{n}(\%)$ & $159(46 \%)$ & $50(83 \%)$ & 49 (58\%) & 41 (39\%) & $19(20 \%)$ \\
\hline 500-1000 meter, $\mathrm{n}(\%)$ & $31(9.0 \%)$ & $5(8.3 \%)$ & $6(7.1 \%)$ & 12 (II\%) & $8(8.4 \%)$ \\
\hline 300-500 meter, n (\%) & $27(7.8 \%)$ & $2(3.3 \%)$ & $10(12 \%)$ & 7 (6.7\%) & $8(8.4 \%)$ \\
\hline 100-300 meter, $\mathrm{n}(\%)$ & $29(8.4 \%)$ & $2(3.3 \%)$ & $5(6.0 \%)$ & $10(9.5 \%)$ & $12(13 \%)$ \\
\hline 50-100 meter, $\mathrm{n}(\%)$ & 47 (14\%) & $\mathrm{I}(\mathrm{I} .7 \%)$ & $7(8.3 \%)$ & $21(20 \%)$ & $18(19 \%)$ \\
\hline 0-50 meter, $\mathrm{n}(\%)$ & $5 I(15 \%)$ & $0(0.0 \%)$ & 7 (8.3\%) & $14(13 \%)$ & $30(32 \%)$ \\
\hline \multicolumn{6}{|l|}{ Self-reported ability to climb stairs $* * *$} \\
\hline$\geq 3$ stairs, $\mathrm{n}(\%)$ & $166(48 \%)$ & 51 (85\%) & $54(64 \%)$ & 41 (39\%) & $20(21 \%)$ \\
\hline 2 stairs, n (\%) & $61(18 \%)$ & $5(8.3 \%)$ & $14(17 \%)$ & $28(27 \%)$ & $14(15 \%)$ \\
\hline I stairs, n (\%) & $69(20 \%)$ & $3(5.0 \%)$ & $12(14 \%)$ & $20(19 \%)$ & $34(36 \%)$ \\
\hline 0 stairs, $n(\%)$ & $48(14 \%)$ & I (I.7\%) & $4(4.8 \%)$ & $16(15 \%)$ & $27(28 \%)$ \\
\hline Self-rated health $100=$ best, $0=$ worst $* * *$, mean (SD) & $60(2 I)$ & $67(20)$ & $64(19)$ & $60(20)$ & $51(22)$ \\
\hline
\end{tabular}

Notes: *Value closest in time to discharge. **Defined as a discharge diagnosis after a previous hospitalization. ***Reported at the day of discharge.

Abbreviations: eGFR, estimated glomerular filtration rate; SD, standard deviation; Q, Quartile. 


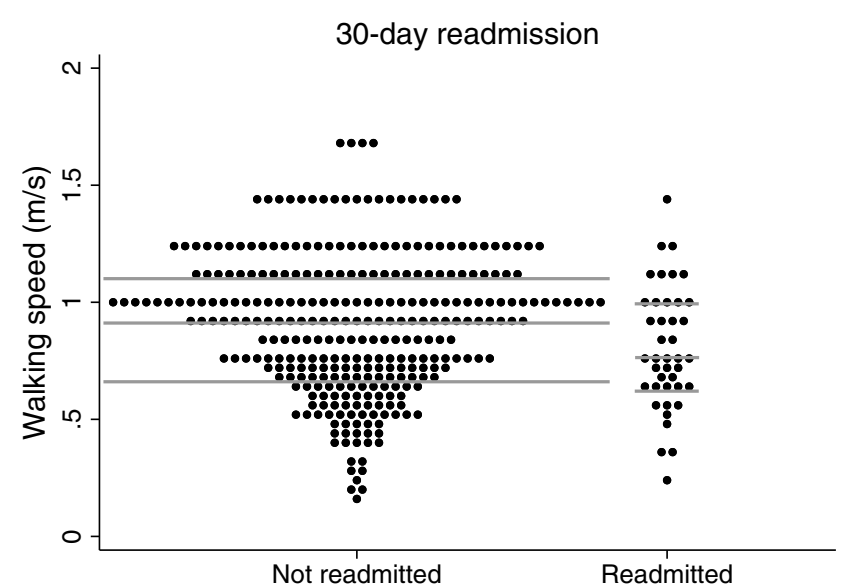

Figure 3 Dots plots showing 10-meter gait speed according to 30-day all-cause non-elective readmission or death. The horizontal lines represent the median, upper and lower quartiles.

days was $0.8 \mathrm{~m} / \mathrm{s}$ (SD 0.3), compared with $0.9 \mathrm{~m} / \mathrm{s}$ (SD 0.3 ) in patients not readmitted. In the quartile with highest gait speed, $13 \%(\mathrm{n}=8)$ were readmitted within 90 days, compared with $31 \%(\mathrm{n}=29)$ patients in the quartile with the slowest gait speed (Table 2). Each $0.1 \mathrm{~m} / \mathrm{s}$ lower gait speed was associated with a $13 \%$ greater odds of 90 -day readmissions (OR 1.13 [95\% CI 1.04 to 1.24]). The odds for 90-day readmission was 2.9 times higher in the quartile with the slowest walkers compared with the quartile with the fastest walkers (OR 2.86 [95\% CI 1.20 to 6.77]).

\section{Discussion}

This was a prospective observational cohort study in a mixed population of patients hospitalized for emergency care including 344 patients from 5 different wards. This is the first study on gait speed and readmission or death in this type of cohort. All included patients performed a comfortable static 10MGS test the same day they were discharged. We found that $10 \mathrm{MGS}$ was significantly associated with 30- and 90-day non-elective all-cause hospital readmission. The results are supported by earlier studies. Kon et al showed that a $4 \mathrm{~m}$ gait speed test was associated with 90-day readmission in patients with COPD. ${ }^{12}$ Another study suggested an association between gait speed and risk of death or hospital readmission among patients post myocardial infarction. ${ }^{10}$ We found that for each $0.1 \mathrm{~m} / \mathrm{s}$ decrease in 10MGS the odds ratio for 30-day and 90-day readmission was 1.13 . Kon et al showed that the odds ratio of readmission at 90 days for each $0.1 \mathrm{~m} / \mathrm{s}$ decline in gait speed was 1.30 (95\% CI 1.14 to 1.48$)$.

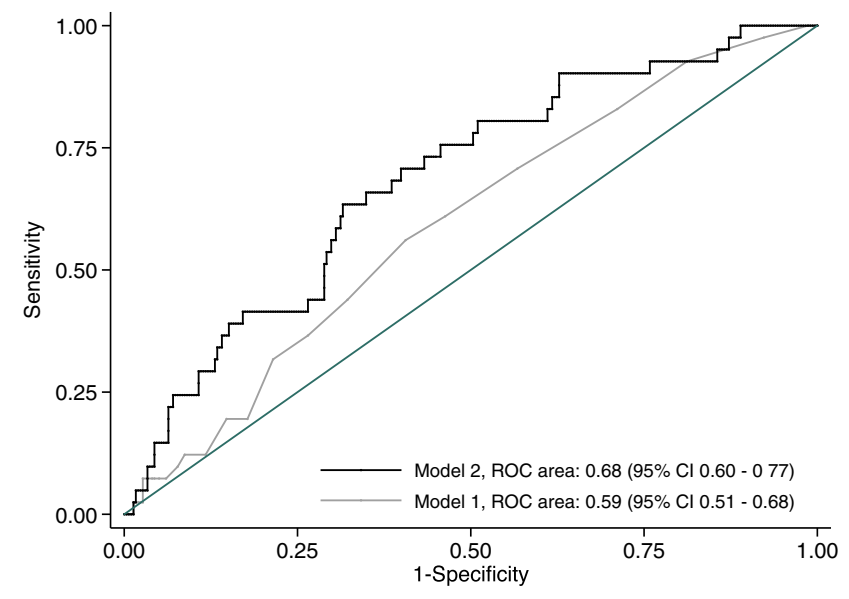

Figure 4 Receiver operating characteristic (ROC) curves demonstrating the ability of the unadjusted and a multivariable adjusted model to predict 30-day readmission. Model I: crude model; Model 2: including age, estimated glomerular filtration rate, hemoglobin concentration, and active cancer.

We hypothesized that the 10MGS would be an indicator of frailty and represent a composite of other risk factors such as age, ${ }^{16}$ comorbidities, and characteristics that may be related to the risk of early readmission. Indeed, we found an association with gait speed and readmission. The study was stopped prematurely which is a limitation. We included 344 patients compared to the aim of including 500 patients. The reason for this was mainly that recruitment was time consuming and further extension of the study period was not possible due to shortage of personnel resources. Nevertheless, there was sufficient power to observe a difference in event rate between those with and without a slow gate speed. Furthermore, we showed was that the test poorly discriminated between those who met the outcome and those who did not (low AUC) and there was no clear cutoff gait speed where both the sensitivity and specificity were high. One explanation could be that the study included a heterogeneous group of patients. Causes of slow 10MGS likely vary between patients and their conditions and might be a stronger predictor for a few specific pathophysiologic conditions. In addition, it is possible that the 10MGS test is not a test for frailty, but shows disease severity in specific conditions such as diseases that limit cardiopulmonary function, for example COPD. ${ }^{12}$ On the other hand, it is still possible that there is mutual sequela found in several diseases after a period of illness such as, systemic inflammation, fatigue or deterioration of homeostasis. In many cases, reasons for readmissions are not related to the initial hospital stay. ${ }^{4}$ Among patients who have been treated for myocardial infarction, half of the readmissions within 30 days are not 
Table 2 Univariate Predictors of 30- and 90-Day Non-Elective All-Cause Hospital Readmission

\begin{tabular}{|c|c|c|}
\hline & $\begin{array}{l}\text { 30-Day } \\
\text { Readmission }\end{array}$ & $\begin{array}{l}\text { 90-Day } \\
\text { Readmission }\end{array}$ \\
\hline & OR, $95 \% \mathrm{Cl}$ & OR, $95 \% \mathrm{Cl}$ \\
\hline Age, years & $1.03(1.00-1.06)$ & $1.03(1.00-1.05)$ \\
\hline Female sex & $0.60(0.30-1.21)$ & $1.06(0.64-1.75)$ \\
\hline Pulse*, beats/minute & $1.00(0.98-1.02)$ & $1.02(1.00-1.03)$ \\
\hline $\begin{array}{l}\text { Systolic blood pressure*, } \\
\mathrm{mmHg}\end{array}$ & $0.99(0.97-1.01)$ & $1.00(0.98-1.01)$ \\
\hline $\begin{array}{l}\text { Diastolic blood pressure*, } \\
\mathrm{mmHg}\end{array}$ & $0.98(0.95-1.01)$ & $0.97(0.95-1.00)$ \\
\hline $\begin{array}{l}\text { Breathing frequency*, } \\
\text { breaths } / \mathrm{min}\end{array}$ & $1.03(0.98-1.08)$ & $1.04(0.99-1.09)$ \\
\hline $\begin{array}{l}\text { Oxygen } \\
\text { saturation*, percent }\end{array}$ & $0.93(0.82-1.05)$ & $1.00(0.90-1.10)$ \\
\hline Body temperature*, ${ }^{\circ} \mathrm{C}$ & $1.65(0.91-2.99)$ & $1.25(0.79-1.97)$ \\
\hline Body mass index*, $\mathrm{kg} / \mathrm{m}^{2}$ & $0.95(0.89-1.01)$ & $0.97(0.92-1.02)$ \\
\hline $\begin{array}{l}\text { Serum C-reactive } \\
\text { protein*, mg/L }\end{array}$ & $1.00(0.99-1.01)$ & $1.00(0.99-1.00)$ \\
\hline $\begin{array}{l}\text { Serum sodium conc.*, } \\
\mathrm{mmol} / \mathrm{L}\end{array}$ & $0.97(0.88-1.07)$ & $0.98(0.91-1.05)$ \\
\hline $\begin{array}{l}\text { Serum potassium conc.*, } \\
\mathrm{mmol} / \mathrm{L}\end{array}$ & $1.60(0.79-3.19)$ & $1.59(0.92-2.74)$ \\
\hline eGFR*, mL/min/l.73 m² & $0.99(0.97-1.00)$ & $0.99(0.98-1.00)$ \\
\hline $\begin{array}{l}\text { Serum leucocyte conc.*, } \\
\text { no. } \times 10^{9}\end{array}$ & $1.03(0.96-1.09)$ & $1.01(0.95-1.07)$ \\
\hline Haemoglobin conc.*, g/L & $0.98(0.96-0.99)$ & $0.98(0.97-0.99)$ \\
\hline $\begin{array}{l}\text { Previous myocardial } \\
\text { infarction** }\end{array}$ & $0.66(0.27-1.65)$ & $0.80(0.42-1.54)$ \\
\hline Heart failure ${ }^{* *}$ & $1.96(0.98-3.90)$ & $2.65(1.55-4.54)$ \\
\hline Diabetes** & $0.89(0.40-1.94)$ & $\mathrm{I} .37(0.78-2.4 \mathrm{I})$ \\
\hline $\begin{array}{l}\text { Chronic obstructive } \\
\text { pulmonary disease** }\end{array}$ & $2.05(0.94-4.50)$ & $1.43(0.74-2.77)$ \\
\hline $\begin{array}{l}\text { Previous atrial fibrillation } \\
\text { or flutter** }\end{array}$ & $0.96(0.45-2.06)$ & $1.60(0.92-2.77)$ \\
\hline Active cancer** & $2.17(1.04-4.55)$ & $2.18(1.20-3.96)$ \\
\hline Previous stroke ${ }^{* *}$ & $1.62(0.63-4.17)$ & $1.34(0.6 \mathrm{I}-2.92)$ \\
\hline Living alone $* * *$ & $1.09(0.56-2.10)$ & $0.99(0.60-1.65)$ \\
\hline Home care service*** & $1.46(0.53-4.08)$ & I.7I (0.76-3.85) \\
\hline \multicolumn{3}{|l|}{$\begin{array}{l}\text { Self-reported use of } \\
\text { walking aid*** }\end{array}$} \\
\hline Never & 1.0 & 1.0 \\
\hline Sometimes & $1.64(0.70-3.88)$ & $1.81(0.91-3.59)$ \\
\hline Always & $1.37(0.56-3.36)$ & $2.31(1.20-4.46)$ \\
\hline \multicolumn{3}{|l|}{$\begin{array}{l}\text { Self-reported walking } \\
\text { distance*** }\end{array}$} \\
\hline$>1000$ meter & 1.0 & 1.0 \\
\hline 500-1000 meter & $2.70(0.94-7.75)$ & $3.69(1.6 I-8.46)$ \\
\hline $300-500$ meter & $0.90(0.19-4.22)$ & $0.89(0.28-2.79)$ \\
\hline $100-300$ meter & $1.80(0.54-5.96)$ & $2.30(0.94-5.62)$ \\
\hline 50-100 meter & $1.34(0.45-3.96)$ & $1.56(0.7 I-3.46)$ \\
\hline 0-50 meter & $3.09(|.29-7.4|)$ & $2.79(1.37-5.68)$ \\
\hline
\end{tabular}

(Continued)
Table 2 (Continued).

\begin{tabular}{|c|c|c|}
\hline & $\begin{array}{l}\text { 30-Day } \\
\text { Readmission }\end{array}$ & $\begin{array}{l}\text { 90-Day } \\
\text { Readmission }\end{array}$ \\
\hline & OR, $95 \% \mathrm{Cl}$ & OR, 95\% Cl \\
\hline $\begin{array}{l}\text { Self-reported ability to } \\
\text { climb stairs*** }\end{array}$ & & \\
\hline$\geq 3$ stairs & 1.0 & 1.0 \\
\hline 2 stairs & $1.42(0.57-3.50)$ & $1.49(0.75-2.96)$ \\
\hline I stairs & $1.06(0.42-2.70)$ & $1.59(0.83-3.06)$ \\
\hline 0 stairs & $2.47(1.04-5.87)$ & $1.72(0.83-3.59)$ \\
\hline $\begin{array}{l}\text { Self-rated health } \\
100=\text { best, } 0=\text { worst } * * *, \\
\text { mean (SD) }\end{array}$ & $0.99(0.97-1.00)$ & $1.00(0.98-1.01)$ \\
\hline
\end{tabular}

Notes: *Value closest in time to discharge. **Defined as a discharge diagnosis after a previous hospitalization. ${ }^{* * *}$ Reported at the day of discharge.

Abbreviations: eGFR, estimated glomerular filtration rate; OR, odds ratio; SD, standard deviation.

related to heart disease. ${ }^{5,6}$ In 2013, Harlan Krumholz, an American cardiologist, described the concept of posthospital syndrome. ${ }^{17}$ He hypothesized that there was something with the hospital stay in itself, not related to the initial cause of hospitalization which led to the increased risk of readmission. He speculated that it could be related to the hospital environment including stress, and sleep disturbance among other things. ${ }^{17}$

The primary aim was to study the association between 10MGS test and readmission or death in a mixed population of patients hospitalized for emergency care. The study was not designed for sub-group analyses, and subgroup analyses are sometimes not recommended due to the risk of fishing for stronger relationships than found in the primary analyses. The results showed that gait speed poorly discriminated between those who met, and those who did not meet the outcome. However, when including age, eGFR, hemoglobin concentration, and active cancer to the logistic regression model it yielded an AUC of 0.68. This suggests that it might be possible to make prediction models for hospital readmission with better discrimination.

The inclusion and exclusion criteria were carefully chosen to simulate a credible clinical setting were the gait speed test could be applied. These selection criteria may, however, have selected a slightly healthier population than all-comers. Therefore, caution should be applied not to apply the test to a very dissimilar population. A healthier population does not confound the association between gait speed and risk of readmission, but it does decrease the statistical power since fewer will experience the outcome. 


\section{Strengths and Limitations}

A strength of the study is the prospective design where all of the included patients were examined the same day they were discharged. The gait speed has also earlier been shown to have a good test-retest reliability in older adults with intraclass correlation coefficient $>0.9 .{ }^{18} \mathrm{~A}$ limitation was that this was a single-center study at a university hospital and the cohort of patients might not be representative to other hospitals. However, we only included patients admitted directly from the emergency department, and the number of special rare elective cases should thereby have been reduced. This is confirmed in the Supplementary Table 1 presenting a diversity of main discharge diagnoses, fulfilling the aim to focus on a general hospitalized population. Furthermore, it should be noted that the point estimate AUCs were calculated in the same population and therefore that the point estimates are likely to be lower in an independent dataset. Another limitation is that many of the included patients had cardiology-related diseases and the study results will therefore not be generalizable to a hospital where these patients are few. Furthermore, few patients were included from the infectious diseases ward.

\section{Conclusion}

In a mixed population of patients hospitalized for emergency care low gait speed at discharge was associated with an increased risk of 30- and 90-day non-elective all-cause readmission. However, the test did not discriminate well between those who were readmitted or died and those who did not, therefore we do not recommend its use as a standalone test in this population.

\section{Funding}

Dr. Daniel Hertzberg has received grants from The Swedish Society of Medicine. Dr. Martin J Holzmann holds research positions funded by the Swedish HeartLung Foundation (grant 20170804), and the ALF agreement between Stockholm County Council and Karolinska Institutet (grant 20170686). No specific funding was obtained for this study.

\section{Disclosure}

Dr. Martin J Holzmann received consultancy honoraria from Actelion, Idorsia and Pfizer. The authors report no other conflicts of interest in this work.

\section{References}

1. Jencks SF, Williams MV, Coleman EA. Rehospitalizations among patients in the Medicare fee-for-service program. $N$ Engl $\mathrm{J} \mathrm{Med.}$ 2009;360(14):1418-1428. doi:10.1056/NEJMsa0803563

2. McIlvennan CK, Eapen ZJ, Allen LA. Hospital readmissions reduction program. Circulation. 2015;131(20):1796-1803. doi:10.1161/ CIRCULATIONAHA.114.010270

3. Allaudeen N, Schnipper JL, Orav EJ, Wachter RM, Vidyarthi AR. Inability of providers to predict unplanned readmissions. J Gen Intern Med. 2011;26(7):771-776. doi:10.1007/s11606-011-1663-3

4. Roger VL. Epidemiology of myocardial infarction. Med Clin North Am. 2007;91(4):537-552. doi:10.1016/j.mena.2007.03.007

5. Go AS, Mozaffarian D, Roger VL, et al. Executive summary: heart disease and stroke statistics-2014 update: a report from the American Heart Association. Circulation. 2014;129(3):399-410. doi:10.1161/ 01.cir.0000442015.53336.12

6. Axon RN, Williams MV. Hospital readmission as an accountability measure. JAMA. 2011;305(5):504-505. doi:10.1001/jama.2011. 72

7. Dharmarajan K, Krumholz HM. Strategies to reduce 30-day readmissions in older patients hospitalized with heart failure and acute myocardial infarction. Curr Geriatr Rep. 2014;3(4):306-315. doi:10.1007/s13670-014-0103-8

8. Ehwerhemuepha L, Finn S, Rothman M, Rakovski C, Feaster W. A novel model for enhanced prediction and understanding of unplanned 30-day pediatric readmission. Hosp Pediatr. 2018;8 (9):578-587. doi:10.1542/hpeds.2017-0220

9. Fonseca Alves DJ, Bartholomeu-Neto J, Júnior ER, Zarricueta BS, Nobrega OT, Córdova C. Walking speed, risk factors, and cardiovascular events in older adults-systematic review. J Strength Cond Res. 2017;31(11):3235-3244. doi:10.1519/JSC.0000000000002182

10. Dodson JA, Arnold SV, Gosch KL, et al. Slow gait speed and risk of mortality or hospital readmission after myocardial infarction in the translational research investigating underlying disparities in recovery from acute myocardial infarction: patients' health status registry. J Am Geriatr Soc. 2016;64(3):596-601. doi:10.1111/jgs.14016

11. Hall WJ. Update in geriatrics. Ann Intern Med. 2006;145:538-543. doi:10.7326/0003-4819-145-7-200610030-00012

12. Kon SSC, Jones SE, Schofield SJ, et al. Gait speed and readmission following hospitalisation for acute exacerbations of COPD: a prospective study. Thorax. 2015;70(12):1131-1137. doi:10.11 36/thoraxjnl-2015-207046

13. Bisca GW, Fava LR, Morita AA, et al. 4-meter gait speed test in chronic obstructive pulmonary disease: interrater reliability using a stopwatch. J Cardiopulm Rehabil Prev. 2017. doi:10.1097/ HCR.0000000000000297

14. Levey AS, Stevens LA, Schmid $\mathrm{CH}$, et al. A new equation to estimate glomerular filtration rate. Ann Intern Med. 2009;150:604-612. doi:10.7326/0003-4819-150-9-200905050-00006

15. The National Board of Health and Welfare. Available from: https:// www.socialstyrelsen.se/english. Accessed October 6, 2018.)

16. Bohannon RW. Comfortable and maximum walking speed of adults aged 20-79 years: reference values and determinants. Age Ageing. 1997;26(1):15-19. doi:10.1093/ageing/26.1.15

17. Krumholz HM. Post-hospital syndrome-an acquired, transient condition of generalized risk. $N$ Engl J Med. 2013;368(2):100-102. doi:10.1056/NEJMp1212324

18. Steffen TM, Hacker TA, Mollinger L. Age- and gender-related test performance in community-dwelling elderly people: six-minute walk test, berg balance scale, timed up \& go test, and gait speeds. Phys Ther. 2002;82:128-137. doi:10.1093/ptj/82.2.128 
Open Access Emergency Medicine

Dovepress

\section{Publish your work in this journal}

The Open Access Emergency Medicine is an international, peerreviewed, open access journal publishing original research, reports, editorials, reviews and commentaries on all aspects of emergency medicine. The manuscript management system is completely online

and includes a very quick and fair peer-review system, which is all easy to use. Visit http://www.dovepress.com/testimonials.php to read real quotes from published authors.

Submit your manuscript here: https://www.dovepress.com/open-access-emergency-medicine-journal 